Dr. Juan Jesús Álvarez Álvarez

Universidad Francisco de Vitoria

@ j.alvarez.prof@ufv.es

(iD) $0000-0003-2049-2228$

Recibido / Received 30 de mayo de 2018

- Aceptado / Acepted 15 de junio de 2018

- Páginas / Pages De la 125 a la 146

n ISSN: 1885-365X

\title{
¿Cómo pensar y hablar sobre Dios, hoy? Bases conceptuales para un diálogo renovado entre razón y fe
}

How to think and speak about God today? The conceptual basis for a renewed dialogue between raison and faith

A partir de un análisis panorámico de la situación actual en el mundo occidental, en donde la reflexión sobre la cuestión de Dios suele ser despreciada o incluso rechazada virulentamente por el surgimiento de un nuevo ateísmo militante, el presente trabajo intenta delinear el marco de comunicación más adecuado para hacer posible hoy el diálogo entre razón y fe. Ello requiere, en primer lugar, un acuerdo acerca de lo que entendemos por Dios. Pero también exige una adecuada comprensión de los conceptos de razón y fe, e incluso una equilibrada idea de diálogo que hagan de este algo factible.

PALABRAS CLAVE: ateísmo, diálogo, Dios, fe, razón.

From a panoramic view of the current situation in the western world, where the reflection about God is usually despised or even virulently rejected due to the emergence of a new militant atheism, this study tries to profile the most suitable framework to enable the dialogue between reason and faith. This requires, firstly, an agreement about the notion of God. But, it also demands to understand appropriately the concepts of reason and faith, and even a right idea of a dialogue which make it something feasible.

\section{Análisis panorámico de la cuestión: el surgimiento de un nuevo ateísmo militante}

Parece claro que la religión no solo desempeña hoy, particularmente en Occidente, un papel poco relevante en la vida social, sino que la misma idea de Dios resulta ajena y a menudo aun lesiva para la mentalidad actual, algo así como un extraño y caprichoso postulado que, además de que no puede ser considerado en absoluto científico, resulta incluso pernicioso para la vida y el progreso humanos; en definitiva, algo de lo que podemos y debemos prescindir, y contra cuya tentación o amenaza hemos de luchar. 
Al respecto de la cuestión de Dios, hemos asistido en los últimos años a una cierta transformación en la actitud que muchos de nuestros contemporáneos adoptan: de una pretendida indiferencia que, abogando por respuestas agnósticas, promovía la consecución de una perfecta instalación en nuestra finitud ontológica que haría incluso innecesaria la pregunta por Dios, hemos pasado al resurgimiento de posiciones ateas, además de corte radical y combativo, anti-teísta. ¿A qué se ha debido este cambio?

\subsection{El ateísmo actual y sus "Razones"}

Es obvio que la posibilidad misma del ateísmo descansa primordialmente en el hecho de que la existencia de Dios no nos resulta evidente. Además, puesto que el alcance y exigencias de la fe (en especial, de la fe religiosa) supera con mucho el de otras propuestas o relatos, menos totalizantes y comprometedores, es comprensible una cierta prevención ante ese tipo de creencia.

Tratar (pensar y hablar) sobre Dios, por otra parte, resulta siempre problemático en mayor o menor medida y por varias razones. En primer lugar, el término "Dios" suele usarse, tanto por los creyentes como por los ateos, de un modo tan recurrente, en circunstancias tan diversas y con tan distintos sentidos, que muchos no dejan de manifestar un cierto cansancio hasta el punto de que ya ni siquiera quieren oír hablar de él.

Debo confesarlo, dice Fabrice Hadjadj, antes de mi conversión detestaba esa palabra. Tenía la impresión de que, cuando alguien decía <Dios>, ponía punto y final a toda conversación. Había introducido fraudulentamente un comodín en la partida. Era un abracadabra, una fórmula mágica (...) una solución final en el seno de la discusión, ahogada de golpe bajo el peso de esa palabrota (...) Cuando era ateo me veía obligado a reconocer un misterio en la existencia. No obstante, pensaba que la palabra <Dios $>$ no tenía nada que ver con ese misterio, que incluso era una forma de esquivarlo (2013, p. 34).

También de este modo, como una fácil e ilusoria salida que nos hace huir de la realidad en lugar de afrontarla, suele ser interpretada toda referencia a Dios entre las personas que quisieran forzar Su naturaleza para hacerla más asequible y controlable, al menos como objeto de su investigación. Así sucede a menudo con aquellos científicos que querrían exigir la imposición de la metodología propia de su disciplina en todos los niveles posibles de realidad antes de admitir que algo con sentido pudiera ser afirmado en ese otro orden. Así sucede, por ejemplo, con el biólogo Richard Dawkins, quizás el ateo hoy más conocido en el mundo entero y el representante de la actitud más extremista que en esta cuestión puede adoptarse (hasta el punto de que pocos de sus colegas, incluso entre los que se manifiestan ateos, le siguen aquí). Criticando lo que él llama la "separación de magisterios", Dawkins dirá:

La presencia o ausencia de una superinteligencia creativa [así es como concibe a Dios] es inequívocamente una pregunta científica (...) Los métodos que nosotros deberíamos usar para resolver estos asuntos, en el improbable caso de que se haga disponible alguna evidencia relevante, serían pura y totalmente métodos científicos (2010, p. 69). 
La confusa idea que muchas personas se acaban forjando de "Dios" como consecuencia del comportamiento de los que dicen seguirle, de la pedagogía religiosa a la que se han visto sometidas o de su propia experiencia personal considerada a la luz de esa determinada imagen, podría ser un tercer factor que influyera en su posterior rechazo. Lo cierto es que toda representación de Dios tiene que ser, tanto por su propia naturaleza como por nuestra condición finita, necesariamente deficiente, limitada, y verse fácilmente expuesta a todo tipo de corrupciones que habría que purificar antes de cualquier reflexión o diálogo. Es un hecho que «el acceso a Dios se vuelve complejo cuando toda relación con él es mediada por algo o alguien que no es Él mismo» (Pastorino, 2016), de manera que no es infrecuente que después de haberse hecho una falsa imagen de Dios que no puede por menos que incluir también ciertos esquemas afectivos, muchos procedan a rechazar virulentamente su existencia pues lo consideran incompatible con sus "razonables y justas" expectativas.

Tampoco es inusual que, dada la singular forma en la que cuestión de Dios se nos plantea (no como una pregunta meramente especulativa sino existencial), los cauces a través de los que nuestra idea acerca de él suele generarse (entre otras cosas, en estrechísima interacción con nuestra forma de ser y con nuestra personalidad) y hasta el modo en que se sustancia nuestra respuesta (en virtud de un acto de elección sustentado en motivos de índole más práctica que teorética), la actitud que se adopte dependa finalmente mucho más de íntimos y secretos motivos que difícilmente pueden ser objeto de análisis, que de razones claras, serenas y suficientemente fundadas desde un punto de vista especulativo.

Prolongando esta línea, otra posible explicación, complementaria con las anteriores pero de ningún modo menor, tiene que ver con el problema del fundamento de la moral, un problema que no solo se refiere al modo en que se supone que hemos de obrar (cuestión ética) sino que conecta también con las preguntas por nuestra identidad como seres humanos (cuestión antropológica) y por nuestro destino último (cuestión escatológica), y cuya resolución se ha visto también sujeta a una evolución histórico-cultural que ha acabado influyendo en la mentalidad hoy dominante en Occidente .

En efecto, si durante mucho tiempo fundamentar la moral fue tarea propia de una metafísica que hundía sus raíces en la Revelación judeo-cristiana y en la concepción de un Dios Creador que nos habría otorgado una naturaleza y un modo de ser propios, querría lo mejor para nosotros (de manera que la exigencia moral, así establecida, no podría verse como algo extrínseco, puramente sobrenatural, opresivo y hasta dañino, sino intrínseco, benéfico y fundado en el ser), a lo largo de la edad moderna se fue difundiendo, hasta prevalecer hoy, la idea de que el hombre constituye el todo del hombre, y de que toda forma de heteronomía en el orden moral era necesariamente contraria a la libertad y al deseo de autonomía e independencia humanos que nos conforman, rasgos que serían a su vez los únicos cauces por los que el hombre podría alcanzar la sola liberación que le es posible esperar y obtener por sí y para sí mismo. Así las cosas,

creemos -dijo Tresmontant hace unos años- que el ateísmo actual encuentra en esta concepción de la ética uno de los motivos más vivos de su dinamismo. Si, en efecto, la exigencia ética no está fundada en la realidad objetiva, en el ser mismo; si viene impuesta desde fuera por Dios (...) como un sistema de prohibiciones; y si no es comprendida en su razón de ser ontológica y ontogenética, como una exigencia 
de desarrollo, entonces, en efecto, la rebelión contra una ley cuyo sentido no se comprende se convierte ya en rebelión contra un Dios que parece ser su autor tiránico (Tresmontant, 1969, pp. 371-372).

El problema del mal es otro de los factores que han predispuesto a muchos hombres al rechazo visceral de un Dios cuya existencia o, peor aún, cuya inocencia consideran incompatible con el sufrimiento frecuentemente "excesivo" $y$, al menos en apariencia, carente de sentido, de un ingente número de seres, estos sí víctimas inocentes. Dicha objeción, esgrimida para renegar de la existencia de un Dios omnipotente, omnisciente y bueno, parece haber alcanzado en los últimos tiempos un especial grado de virulencia, habida cuenta del cada vez más profundo y cercano conocimiento de los males que acechan al ser humano en cualquier lugar del mundo.

Se dirá, por último, que la animadversión, junto con la agresividad que hoy muchos muestran cuando las cuestiones teológica y religiosa parecen asomar en la escena, tiene que ver con razones de índole doctrinal y sobre todo con situaciones de hecho que nos indicarían no solo lo inútil de dichos planteamientos sino su carácter pernicioso: el terrorismo que dice apoyarse en motivaciones religiosas, el comportamiento tanto inmoral como delictivo de algunos de los que se deberían mostrar especialmente ejemplares en el cumplimiento de sus deberes teniendo en cuenta la autoridad de la que se ven investidos y el hecho de ser representantes de sus respectivas confesiones, la posición crítica que las religiones suelen mostrar en relación con determinadas acciones frente a las que la mentalidad actual parece ser especialmente sensible hasta el punto de que frecuentemente se plantean en forma de derechos (el aborto o la conducta homosexual, por ejemplo) etc.,

\subsection{La NECESIDAD DE UNA MiRAda MÁs PENETRANTE}

Sin embargo, no me parece que atendiendo exclusivamente a razones de este tipo se pueda explicar el cambio de actitud al que al principio de este trabajo aludí. Por un lado, tanto el contenido suprarracional de la fe religiosa como su particular exigencia teórico-práctica forman parte de su naturaleza inmutada y, en todo caso, podrían favorecer con mucha más lógica al agnosticismo que al ateísmo. Es sumamente cuestionable, además, que el ateísmo no plantee de hecho exigencias tan radicales como la fe religiosa; que, al menos cuando busca sustituir a esta, no adopte a su vez una matriz y un talante también religiosos; y que, sea como fuere, no requiera de un acto de fe-aunque en sentido inverso- de similar carácter ( $y$ en algunos casos, puede que incluso menos razonable) que el acto de fe propio de la creencia religiosa.

En cuanto a la cuestión del mal, resulta obvio que si se plantea en forma apasionada y vehemente es porque, antes que una temática de carácter especulativo ante cuya incomprensión puede suscitarse un punzante escándalo intelectual con repercusiones incluso de alcance teológico, se nos presenta y lo sufrimos en el plano de la experiencia como algo contra lo que los deseos y esperanzas humanas acaban siempre estrellándose hasta el extremo de afectar gravemente nuestras expectativas de un sentido para la existencia. Pero, 
como quiera que sea catalogado -problema ininteligible e irreconciliable con la existencia de Dios para unos, misterio sobreinteligible que solo puede tener sentido si Dios existe para otros-, es una permanente amenaza para todos, creyentes y no creyentes, que todos antes o después acabaremos experimentando y habremos de afrontar.

Muchos de los otros intentos de explicar el resurgimiento del ateísmo militante al que nos hemos referido tienen en realidad un mero carácter circunstancial y/o no son otra cosa que elementos de juicio segundos que siguen a una toma de decisión previa de carácter moral, más que filosófico o científico. Solo esta toma de postura en forma de pre-juicio podría dar razón satisfactoriamente de actitudes tan agresivas, incluso contra algunos de sus propios colegas, como las de Dawkins, o de las protestas que impidieron a Benedicto XVI impartir una conferencia en la Universidad de La Sapienza de Roma, a la que había sido invitado'.

Del mismo sesgo son las acusaciones relativas a la impropia conducta de los creyentes, especialmente de aquellos que tienen una singular autoridad y una especial función dentro de una determinada confesión. Ciertamente, desde el punto de vista psicosociológico, esos motivos concretos que antes mencioné como obstáculos para la fe e incluso como propulsores de desconfianza, pueden tener una importante incidencia sobre la disponibilidad a la creencia. Sin embargo, una cosa es la posible pérdida de credibilidad social del magisterio religioso resultante de esa falta de coherencia y otra muy diferente el "odium fidei" que parecen "destilar" muchos de los ateos de hoy y que compromete seriamente su objetividad.

Tiene que haber razones más profundas que las enunciadas, que puedan ayudarnos a entender esa especial sensibilidad contraria a las creencias religiosas y a la idea de Dios que muchos muestran hoy.

\section{Una mentalidad pre-atea}

Por mi parte, y a título de hipótesis, haré ahora dos observaciones que, sin desdeñar lo anterior, creo que explican mejor y más profundamente las dificultades e incluso el rechazo interior que la mentalidad contemporánea occidental experimenta a la hora de afrontar la cuestión de Dios, ya desde un punto de vista intelectual, como primer paso para un planteamiento más hondo y comprometido. Será a partir de ellas, como contrapartida, como formularé en su momento dos propuestas relativas a los modos que considero más apropiados para "pensar y hablar sobre Dios, hoy".

\footnotetext{
1/ Respecto de este último caso, un matemático judío como Giorgio Israel, a la sazón profesor de la Universidad en la que iba a tener lugar la citada conferencia, comentaba la carta pública de uno de los opositores a la visita en los siguientes términos: «Lo <peligroso> [para los que rechazaban la visita del Papa a una universidad pública y laica] es el hecho de que el Papa trate de abrir el diálogo entre fe y razón, que restablezca la conexión entre las tradiciones judeo-cristiana y griega, y que afirme que ciencia y fe no están separadas por una pared impenetrable, [por tanto] la oposición a la visita del Papa no está motivada por un principio abstracto de secularismo. La oposición es de naturaleza ideológica y tiene a Benedicto XVI como objetivo específico por hablar sobre la ciencia y la relación entre esta y la fe, en vez de limitarse a hablar sobre fe» (Israel, 2008).
} 


\subsection{El preateísmo de La inteligencia de hoy}

En primer lugar, más allá del hecho de que la condición última de posibilidad del ateísmo se funde en que la existencia de Dios no nos es "inmediatamente evidente", se ha impuesto en nuestro tiempo un cierto modo general de operar por parte de la inteligencia, una cierta forma de concebir la razón, que ha servido de caldo de cultivo para el surgimiento de actitudes y filosofías propensas al rechazo de toda forma de fe sobrenatural. Maritain lo llamó "preateísmo de nuestra inteligencia actual" y habló a este respecto de dos tendencias sintomáticas en el uso práctico del intelecto que esconderían un verdadero ateísmo embrionario: el "productivismo mental" y la "primacía de la verificación sobre la verdad".

a) La primera se expresaría en un afán insaciable de producir signos, de establecer fórmulas y de juzgar de acuerdo con preconcepciones de la realidad que oscurecerían esta y harían inviable nuestro acceso a ella. Siguiendo los cánones propios de las ciencias físico-matemáticas, la realidad sería interpretada de acuerdo con una racionalidad intrínseca estructurada de manera matemática y simbolizada por medio de lenguajes formales que la harían supuestamente más "manejable"; las relaciones causales serían reemplazadas por meras fórmulas de función, los conceptos por sus significantes. En más de una ocasión se ha empleado la expresión "olvido del ser" para referirse a esta actitud. Pero, a menudo, no se trata tanto de un olvido cuanto de una reducción ontológica que acaba menoscabando incluso el carácter explicativo de las propias teorías científicas, convertidas entonces en simples medios por los que nos "hacemos cargo" de cómo funcionan y, consecuentemente, de cómo pueden ser usadas las cosas, sin que seamos capaces de conocer lo que son en sí mismas.

Si esto sucede con la realidad que se supone que nos es más cercana, ¿qué ocurrirá entonces con un Dios, concebido como Ser trascendente, y con la particular forma de conocimiento que nos permitiría "conectar" con Él, la fe? Como es lógico, todo lo relativo a ese Dios será juzgado como un problema a-científico o pre-científico, y esa fe como una vivencia meramente subjetiva que no nos permite alcanzar certeza alguna y que, por tanto, no merece la pena considerar seriamente. Incluso entre aquellos que no muestran una cerrazón absoluta a la propuesta religiosa uno entiende entonces que, dadas estas circunstancias, el hombre de hoy en Occidente esté mucho más abierto a formas de religiosidad etérea, líquida; o que resulten más atractivas para él las religiones orientales, a las que se dispensa una cierta complacencia acrítica pues se les atribuye una mentalidad simbólica contrapuesta a la fría mentalidad lógica en la se que supone que -de acuerdo con esa interpretación- se apoyaría por ejemplo el cristianismo.

b) La segunda tendencia, que deriva de la anterior, se expresaría en un mayor interés por verificar experimentalmente la validez y eficacia de los símbolos que producimos que por alimentarnos de la verdad que pudieran llegar a revelarnos. Esta actitud, que conlleva el fatal olvido del concepto de verdad o su reducción a concepciones de esta que se presumen no "dogmáticas", como el relativismo o el subjetivismo, propias de actitudes positivistas, desnaturaliza la filosofía limitando su función al análisis del 
lenguaje, la hermenéutica o el mero planteamiento de preguntas. Pero también afecta a una reflexión con pretensiones sapienciales como, por ejemplo, la teología cristiana, imposibilitando cualquier mínima aprehensión de la verdad divina a través de la Revelación, e incluso la comprensión y acogida en la historia de la presencia de hechos escatológicos, salvíficos y definitivos. En el mejor de los casos, el resultado, desde el punto de vista de la creencia religiosa, será una fe mecánica y conformista; y desde la perspectiva de la praxis, una obediencia puramente formal, el frío cumplimiento de preceptos que me son ajenos y se me presentan como coercitivos, pero que acepto por costumbre o tradición; en definitiva, algo muy cercano ya al ateísmo práctico, que manifiesta creer en Dios pero que se desdice de esa fe sin alma en los actos y aun en la vida que promueve.

\subsection{El REchazo de NUESTRA COMÚn naturaleza humana}

Este olvido del ser y de la verdad acerca de él -es mi segunda observación- no ha dejado de manifestarse igualmente respecto de nuestra propia condición de seres humanos, eliminando toda referencia a una común naturaleza en la que habríamos de bucear para descubrir lo que somos y podemos llegar a ser, cómo hemos de obrar y lo que podemos esperar de nuestro futuro. Ante las perspectivas que se dibujan a medio plazo, hasta la noción misma de ser humano corre el riesgo de verse puesta en tela de juicio y ser sustituida por otra noción -se dice- mucho más dinámica y siempre en progreso: vivimos en una era que anticipa lo "transhumano" y en la que el concepto de persona se ve amenazado con la pérdida de todo sentido definido y su sustitución por algo con un carácter mucho más difuso y "plural" que no se es sino que, en todo caso, incluso seres no propiamente humanos podrían llegar a ser.

En esas condiciones, no nos puede sorprender que temáticas tan cruciales como la pregunta por el sentido de la existencia o el deseo de felicidad se vean así postergadas o minusvaloradas como algo ilusorio, absurdo, o incluso como fuente de frustraciones personales y conflictos sociales. Junto a ellas, también resultarán devaluados o serán objeto de especial rechazo los planteamientos de la cuestión de Dios, muy en particular aquellos que se hallan conectados con las inquietudes más profundas de ese ser humano, problemático, que no se conforma con sobrevivir y que experimenta aspiraciones que superan de forma patente lo que es capaz de procurarse por sí mismo, y al que parecemos querer evitar o recrear mediante una artificiosa labor de ingeniería.

Constato con gran tristeza y preocupación -dice el Cardenal Müller- que muchos de nuestros coetáneos, educados en un mundo sin Dios, desconfían de que la historia, incluso su misma historia personal, tenga una trama, un origen y un destino. El pasado personal, familiar o del propio pueblo se experimenta a modo de ráfagas inconexas, conformándose con pequeños relatos que solo contienen esperanzas raquíticas y no con un relato noble que les eleve, que dé sentido a toda su vida, que explique por qué están aquí, para quién viven, por qué sufren (...) En realidad, al rechazar la fe en Dios -añade- (...) al perder nuestra memoria fundante; al olvidar que Él es nuestro principio y fundamento, nos hemos vuelto pequeños dioses, rehusando profundizar en nosotros mismos para acabar redefiniendo nuestra identidad a nuestro capricho (Müller, 2016, p. 8). 
Ese rechazo resulta hasta cierto punto "lógico" pues, efectivamente, cuando uno se preocupa por el ser y el destino del hombre, nada hay tan decisivo, arriesgado, comprometedor $\mathrm{y}$, en cierto modo, incómodo, como la pregunta por Alguien que habría creado al género humano y que serviría de luz, guía y término a su vida. Hablo aquí de incomodidad porque, frente a los que suponen que la fe es un analgésico que serviría a los creyentes para obviar las dificultades y males de este mundo en lugar de arrostrarlos, la pregunta por un Otro del que el hombre dependería radicalmente y por el que habría sido llamado a la existencia, cuestiona esa supuesta autosuficiencia humana que sirve de punto de encuentro a buena parte de las ideologías de nuestro tiempo y cuya proclama parece hacernos sentir tan orgullosos, aunque eso suponga cancelar tanto nuestra sed de absoluto como la esperanza de que algo o Alguien pueda saciarla.

Por lo demás, si es verdad, como creo, que la idea que el ser humano tiene de sí mismo y la idea que tiene de Dios están estrechamente relacionadas, la huida de sí llevada a cabo por el hombre ha de implicar necesariamente la huida ante un Dios personal al que el hombre no le resulta indiferente y que, precisamente por ello, tiene un plan sobre el mundo que toma en cuenta la libertad humana, ha intervenido decisivamente en la historia y sigue gobernando ambos con su providencia amorosa.

\section{Desbrozando el terreno y poniendo nuevos cimientos}

Si este análisis es correcto, cabe ahora plantearse la cuestión que sirve de título a este ensayo: ¿cómo pensar y hablar sobre Dios, hoy? En realidad, esta pregunta presupone otras sin las que parece difícil que aquella pueda ser abordada con esperanzas de éxito: ¿En qué y sobre qué Dios estaríamos pensando y hablando? ¿Cómo habría que interpretar este pensar y hablar de modo que pueda recuperarse el necesario diálogo entre razón y fe que parece hoy clausurado? Y, por fin, ¿sobre qué cimientos asentar esa comunicación dialógica?

Para responderlas, en este apartado intentaré fijar en primera instancia qué entiendo por "Dios". Después, presentaré otros pre-requisitos necesarios, dadas las circunstancias, para aproximarnos a ese objeto de reflexión planteado al menos a título hipotético, de manera que el diálogo que buscamos sea factible. Se traducen en una concepción adecuada de la razón y de la fe. Finalmente, ya en un nuevo apartado, abordaré las dos propuestas más arriba mencionadas para desarrollar ese diálogo, que están directamente relacionadas con mis observaciones acerca de la difusión del actual ateísmo militante.

\subsection{Sobre LA NOCIÓN DE Dios}

Muchas de las infructuosas discusiones que giran alrededor de la temática de Dios, ya lo he apuntado, derivan de la ambigüedad con la que a menudo usan este término tanto los creyentes como los ateos. Entre los primeros, hay obviamente muy diversas concepciones derivadas de la filosofía o de las variadas confesiones religiosas a las que pueden adherirse. 
Incluso dentro de una misma religión, las formas en las que se concibe o interpreta la figura de Dios no siempre es exactamente la misma si atendemos a la mentalidad propia de cada época o a la sensibilidad y educación de cada creyente. Pero tampoco entre los ateos hay unanimidad a la hora de fijar con precisión el objeto de su rechazo y, a menudo, esa negación se corresponde con una imagen más imaginaria que real de lo que suponen que los creyentes entienden por Dios y aun de los motivos por los que la fe en Dios habría surgido en ellos.

A eso habría que añadir el uso abusivo que algunos -creyentes y/o ateos- hacen del nombre de "Dios" hasta el extremo de llegar a banalizarlo. Entre los creyentes, los fundamentalistas suelen usar ese término como comodín que sirve para todo -defender o atacar, según el caso-. Como ingrediente esencial y casi único de su discurso, Dios, lejos de servir de estímulo y de luz para la búsqueda de la verdad, entorpece, cuando no cierra en falso, dicha búsqueda; en lugar de abrirnos al misterio, lo "resuelve" demasiado fácilmente y, con ello, acaba anulándolo. Pero también el ateo, a menudo, abusa de ese nombre utilizándolo con demasiada ligereza hasta el punto de dar la impresión de padecer una cierta obsesión en su repulsa, como si no pudiera prescindir de él.

Resulta esencial, por tanto, caracterizar con la máxima claridad posible el significado del término. Para no complicar en exceso este punto, me serviré de una propuesta ya clásica, la que sugirió Frederick Copleston en su famoso debate con Bertrand Russell acerca de la existencia de Dios y que este -que se confesaba agnóstico o ateo, según el caso- aceptó sin reservas: «un ser personal supremo, distinto del mundo y creador del mundo» (1978, p. 11).

Es claro que a lo que aquí se hace referencia es a una concepción monoteísta de Dios, considerado Este a título de ser personal, creador y trascendente. Además, en su condición de ser personal se halla implícita su subsistencia, su inteligencia, su libertad y su capacidad de amar. Se esboza así un retrato que, puede objetarse, no solo no hace justicia a concepciones deístas o panteístas sino que tampoco sirve para englobar la idea que de lo divino tienen las múltiples formas de paganismo que hoy parecen volver a florecer, o las religiones orientales. Es cierto. Sin embargo, cuando los ateos de hoy se revuelven contra Dios no suelen tener en mente estas otras expresiones, a las que consideran -según el caso- o mera superstición, o admisibles en la medida en que se pueden conjugar con el materialismo (es lo que ocurre con los "panteísmos naturalistas") o, en el fondo, simplemente ateas, y con las que en cualquier caso se muestran mucho más tolerantes; se refieren particularmente al Dios del monoteísmo de tradición abrahámica, y la forma en que lo conciben no difiere mucho de la que aquí se ha propuesto ${ }^{2}$. Es este "Dios de la fe", que no sería otra cosa que una invención humana expresión de nuestros miedos y limitaciones (especialmente dañina en el caso del Dios bíblico, judeocristiano), el que provoca en ellos un rechazo visceral pues -arguyen-contraría y obstaculiza el progreso científico; es fuente de dogmatismo, intolerancia y violencia; resulta incompatible con la existencia del mal; suscita en el ser humano la negación de lo que es más valioso y placentero en la vida; y acaba volviéndose contra el propio hombre remitiendo a este a un ilusorio más allá que no solo actúa como un falso y alienante consuelo sino que le aleja de las verdaderas cuestiones del mundo.

Sin embargo, este Dios, al que se dibuja además como un tirano moralista que coarta

2/ Dawkins, de manera más o menos similar, lo define como «Inteligencia sobrenatural y sobrehumana que deliberadamente diseñó y creó el universo y todo lo que hay en él, incluyéndonos a nosotros» (2010, p. 40). 
nuestra libertad y que pretende imponer su voluntad de un modo irracional, poco tiene que ver con la imagen que desde sus orígenes singularmente el cristianismo ha mantenido. Como ha mostrado Josef Ratzinger, fue de hecho la síntesis entre la filosofía helenística y la fe bíblica, enmarcada dentro de la más amplia unidad de relación entre razón y fe, la que dio lugar a esa concepción de Dios. Así, por una parte, el cristianismo primitivo optó por el Logos, el Dios de los filósofos, frente a los dioses propios de las antiguas religiones, contribuyendo a la desmitologización tanto del mundo como de la propia religión que desde siglos antes ya estaba siendo llevada a cabo por el pensamiento racional. Pero, al mismo tiempo,

dio a ese Dios un significado nuevo, lo sacó del terreno puramente académico y lo transformó profundamente. Ese Dios, que antes parecía totalmente neutro, concepto supremo y definitivo; ese Dios, que se concebía como puro ser o puro pensar, eternamente recluido en sí mismo, sin proyección alguna hacia el hombre y hacia su pequeño mundo; ese Dios de los filósofos, pura eternidad e inmutabilidad que excluye toda relación con lo mudable y contingente, es ahora para la fe el hombre Dios, que no es solo pensar del pensar, eterna matemática del universo, sino también agapé, potencia de amor creador (Ratzinger, 2005, p. 122).

Lejos, pues, de pretender enfrentar al Dios de los filósofos con el Dios de la fe, el cristianismo se presentó ante el mundo, y desea ser entendido desde entonces, "como la verdad que salva»; una verdad razonable, «que hace creíble su pretensión de ser la religio vera recurriendo al discurso racional» (Rodríguez Duplá, 2006, pp. 12-13), pero que a la vez nos supera infinitamente y, por eso mismo, quizás sea la propuesta más acorde con nuestra pascaliana condición, la del ser que tiende a superarse infinitamente a sí mismo.

Concibiendo a Dios de este modo, seguramente no desaparezca el vértigo que nos produce a todos pronunciar su nombre, pero quizás sí ciertos prejuicios y aparentes sinsentidos que hacen enormemente difícil la reflexión y el diálogo pues enseguida cristalizan en pura ideología y en posiciones fundamentalistas -creyentes o ateas, a estos efectos da lo mismo-. El primero de esos prejuicios, y quizás el más importante, la presunción psicologista de que Dios y la religión no son otra cosa que respuestas o productos ilusorios generados por el propio hombre a partir de alguna forma de negatividad inherente a nuestra condición mortal, contingente y, para los fundamentalismos religiosos, esencialmente pecadora. Pero, ¿ha de ser necesariamente así? ¿En dónde radica el origen último de la verdadera idea de Dios y de la religión?

Mi propuesta consiste en que dicho origen no se halla tanto en la reacción a algún tipo de necesidad artificiosa y meramente subjetiva (o al miedo) cuanto en la "revelación" ante un deseo o aspiración a objetivos, que descubro en la "estructura" de mi ser frente el estímulo y el atractivo que la realidad me inspiran y que me provocan tanto una respuesta de estupor como la subsiguiente búsqueda de la verdad más profunda de lo real. Como ha dicho Giussani,

es bastante superficial repetir que la religión ha nacido del miedo. El miedo no es el primer sentimiento que experimenta el hombre. El primero es el atractivo; el miedo aparece en un segundo momento, como reflejo del peligro que se percibe de que la atracción no permanezca. Lo primero de todo es la adhesión al ser, a la vida, el estupor frente a lo evidente; con posterioridad a ello, es posible que se tema que esa evidencia desaparezca, que ese ser de las cosas deje de ser tuyo, que no ejerza 
ya atracción en ti (...) La religiosidad es, ante todo, la afirmación y el desarrollo del atractivo que tienen las cosas. Hay un asombro primero ante la evidencia que caracteriza muy bien la actitud del verdadero investigador: la maravilla de algo presente me atrae, y como consecuencia se dispara en mí la búsqueda. El miedo es una sombra que cae como segunda reacción. Temes perder algo solo cuando lo has tenido al menos un momento (2000, p. 147).

En este sentido, es la experiencia acerca del cosmos que me sobrecoge, del mundo en el que vivo y de lo paradójico de mi propio ser, factores objetivos que se presentan como misterios siempre interpelantes, la que me mueve a postular hipotéticamente y por vía de analogía la existencia de un Otro que pueda fundar y sostener positivamente toda realidad (Dios), y de un cauce para que mi relación con Él pueda desarrollarse en plenitud (religión). De ahí que se pueda decir también que

la única condición para ser siempre y verdaderamente religiosos es vivir intensamente lo real. La fórmula del itinerario que conduce hacia el significado de la realidad es vivir lo real sin cerrazón, es decir, sin renegar de nada ni olvidar nada (...) Cuanto más viva uno con este nivel de conciencia su relación con las cosas, más intensamente vivirá su impacto con la realidad y más pronto comenzará a conocer algo del misterio (...) He aquí, pues, la conclusión: el mundo, esta realidad con la que nos topamos, es como si en el impacto liberase una palabra, una invitación, como si nos hiciese presentir un significado. El mundo es como una palabra, un "logos", que requiere, que remite a otra cosa diferente, que está más allá de sí mismo, más arriba (Giussani, 2000, pp. 156-57).

Esta perspectiva, me parece, no solo cambia la vivencia que el creyente puede tener de lo religioso, haciéndola más rica y profunda, sino que nos permite alumbrar la esperanza de que el ateo contemple este ámbito de otro modo, con otros ojos; o de que, al menos, no adopte frente al verdadero creyente una actitud de prepotencia y desdén demasiado precipitados. ¿Acaso no hay creyentes necesitados de dicha purificación liberadora y ateos en los que se percibe con nitidez esa actitud, ya de alguna manera "religiosa"?

En definitiva, después de lo dicho, la importancia de delimitar con claridad lo que se entiende por Dios ha quedado, creo, suficientemente probada. He propuesto y matizado, además, una noción de Dios que me parece un buen punto de partida para el diálogo. Por último, espero que haya resultado igualmente patente que tanto la posición que uno adopta ante el misterio de lo real como el modo en que se concibe y lo que se espera del Misterio por ese medio verosímilmente alumbrado, son otras variables significativas que pueden hacer posible el diálogo o, por el contrario, convertirlo en inviable de una vez y para siempre ${ }^{3}$.

\footnotetext{
3/ A la hora de pensar y hablar de Dios, el léxico, la semántica, parece tener una importancia decisiva. De hecho, ha confesado Hadjadj:

«Mi conversión fue inicialmente una conversión de vocabulario (...) [Antes] pretendía explicar la presencia en el léxico de la palabra Dios como un intento de finta: negación de la muerte, voluntad de poder, huida al más allá, sublimación neurótica del ¡<socorro-mamá-papá>!... ¿Qué ocurre hoy? Desapareció ese contrasentido. Esa palabra ya no me suena como un tapa-agujeros sino como un abre-abismos. Algunos,
} 


\subsection{Sobre LA RAZÓN, LA FE y EL diálogo ENTRE AMBAS}

¿Basta con esto? ¿No habrá pre-requisitos de otro orden que puedan ser igualmente importantes? Que sea necesario fijar de antemano el objeto de nuestra reflexión y diálogo, que incluso nos pongamos de acuerdo en un cierto saber acerca de aquello sobre lo que vamos a pensar y hablar es condición "sine qua non" de nuestro común discurso, pero ¿será también condición suficiente? Me temo que no. Qué entendemos por ese "pensar" y sobre qué presupuestos epistemológicos habría de asentarse, cómo predisponer adecuadamente al diálogo de modo que ese hablar sea fructífero y de qué modo afrontar esa conversación, también son cuestiones que hemos de tratar irremisiblemente. En este punto, abordaré los dos primeros asuntos que acabo de mencionar. Los plantearé así:

1. Si, en última instancia, lo que queremos es hacer posible la interlocución entre razón y fe, ¿de qué razón y de qué fe se trataría aquí?

2. ¿Cómo concebir ese pretendido diálogo?

\subsubsection{Concepciones de la razón y de la fe en nuestro pensar y hablar sobre Dios}

1. Hay, obviamente, muy diversos modos de concebir la razón que, históricamente, han ido constituyendo la mentalidad de la que hoy somos en general partícipes. Pero es más que probable que no todos sirvan para lo que estamos buscando ni hagan justicia a nuestra experiencia.

a) No podría servir para nuestro propósito, por ejemplo, una razón criticista concebida al estilo racionalista, que pretenda reducir todo conocimiento a ideas "claras y distintas", o que exija para escapar de la duda sistemática y universal una evidencia absolutamente objetiva. Dicha razón, la razón ilustrada que -como medio de saber y de poder- ha animado en buena medida la modernidad, se mostraría radicalmente insuficiente para pensar sobre Dios pues Dios, tal como aquí lo hemos caracterizado, nos trasciende infinitamente e interpela todo nuestro ser, también nuestra libertad. En realidad, sería inhábil incluso para acceder al campo de nuestra propia experiencia personal que,

sin duda, la usan como un tapa-agujeros (creyentes o no, indiferentemente). Apenas la entienden. No perciben su música, por así decir. Porque el significante $<$ Dios $>$ no procede de un deseo de solución final: proviene del reconocimiento de una abertura irreversible. Surge más como una llamada que como una respuesta. Designa la evidencia de lo que se me escapa, la exigencia de lo que me sobrepasa (...) . Cuando la entendemos bien, esa palabra nos deja boquiabiertos. Es la palabra que nos dice que nosotros no tenemos la última palabra. Es un Nombre que no conlleva la clausura del diálogo, sino la hospitalidad para con lo que nos altera, para con lo que nos abre, para con lo que nos sorprende y nos dispone a todo encuentro. El Nombre de Dios no podría hacernos autosuficientes y soberbios; humildemente entregado a nuestros discursos, reclama ante él nuestra humildad. Quien lo blanda para golpear con él como lo haría con una maza no solo es un pesado: está completamente atolondrado» (Hadjadj, 2013, pp. 34-35). 
lo sabemos de primera mano, se nos muestra como una realidad irreductible a todo formulismo y a cualquier esquema puramente racionalista. Los dos ámbitos citados quedarían encerrados en el marco de lo "irracional", que es el término que esa Razón ha acuñado para consolidar su propia autolegitimación.

b) Otra forma de concebir la razón, hoy dominante especialmente en el campo de la divulgación científica y, en gran parte, heredera de la razón ilustrada, es la razón positivista e instrumental, que abdica o incluso reniega de la dimensión sapiencial de la ciencia marginando la búsqueda de la verdad más profunda de las cosas, de su significado, en beneficio de intereses y objetivos con frecuencia meramente pragmáticos o tecnocráticos.

Por las limitaciones que derivan de su propia naturaleza y metodología, pero también como consecuencia de postulados y preconcepciones adoptados por algunos científicos que no tienen por qué seguirse de aquellas y que obedecen en realidad a falsos prejuicios filosóficos, no es inusual que la ciencia se vea así abocada a posiciones que reducen no solo su campo de estudio sino tanto la realidad en su conjunto como la experiencia que el ser humano puede hacer de ella al orden de lo material y de lo que es verificable experimentalmente, al tiempo que acaban sojuzgando la misma ciencia a la tecnología 4 .

La consecuencia para la cuestión que aquí nos ocupa es obvia: desde esta perspectiva cientificista, en el mejor de los casos, ciencia, filosofía y religión podrían compararse con líneas paralelas que nunca entran en conflicto, eso es verdad, pero que tampoco pueden establecer diálogo fecundo alguno.

c) En el extremo opuesto -aunque frecuentemente los extremos se tocan y son el resultado de un movimiento pendular o de una huida hacia adelante- está la razón posmoderna, la razón del pensamiento débil, maestra en el arte de la sospecha, que desconfía de todo relato especulativo y/o programático con intenciones totalizantes, de toda verdad última pretendidamente absoluta e inmutable, de toda búsqueda de significado.

Esta razón, que podríamos denominar también "razón sentimental" pues a menudo termina entregándose complacientemente en brazos del "corazón" (o del instinto), toma lo que uno siente como criterio de discernimiento tanto en el orden especulativo como en el práctico y cuestiona cualquier otro posible medio de entrar en contacto con lo real. El problema, entonces, es que, aunque el sentimiento acompaña sin duda, de diversos modos, a todo acto de conocimiento (también, como veremos, a la fe), pues el sujeto de esos actos es la persona entera, ni el conocimiento se puede reducir sin graves

\footnotetext{
4/ Recordando a Habermas, y en conversación con el científico Gómez Cadenas, el teólogo Javier Prades, ha dicho a este respecto: «intentar pasar desde la explicación científica de un punto particular a una tesis totalizadora no es ciencia sino mala filosofía. El hombre de ciencia puede y debe hacer ciencia, y de ahí se seguirán normalmente consecuencias buenas en su ámbito. Pero si en cuanto científico transita de este punto de la explicación científica a una explicación completa de la realidad, se produce un salto injustificado. Y si lo que se quiere sostener es que la ciencia en cuanto tal es la explicación universal de todo, esa no es una afirmación científica» (Fernández Recuero, 2016).
} 
perjuicios al sentimiento ni la experiencia humana puede interpretarse exclusivamente en clave afectiva o tendencial.

d) Todos estos modos de concebir la razón se nos muestran como alicortos pues, en realidad, la exigencia más estructural de la razón es la de descubrir el significado de las cosas. ¿Será posible satisfacer esa exigencia? Es difícil saberlo con seguridad. Pero lo que sí sabemos a ciencia cierta es que, si queremos mantener la esperanza de lograrlo, si nos proponemos pensar y hablar sobre Dios, si buscamos algún acceso a la singular experiencia humana de la que las religiones positivas nos dan testimonio, nos hace falta superar los prejuicios que quizás puedan obedecer a una parte de esa experiencia pero que no responden a su totalidad, y evitar las posiciones ideológicas que muchas veces construimos a partir de aquellos mismos prejuicios y que nos mueven a desterrar esas cuestiones "demasiado humanas" a oscuros territorios en los que permanecerán para siempre herméticos.

Con ello, no abogo por reclamar un trato especial para el ámbito, supuestamente más allá del límite de lo que se puede pensar y decir, de lo que todavía hoy muchos consideran irracional. Como ha dicho Eugenio Trías, de lo que se trata es de mostrar

la necesidad lógica que un nuevo concepto de razón, o de logos dialógico, posee en relación con esa apertura y con ese acceso metódico hacia el cerco encerrado en sí o hacia el cerco hermético. Esa necesidad lógica perfila, entonces, una idea diferente de logos o de razón (...) un logos que debe acceder al limes, y que en ese limes se abre a su exceso y desbordamiento (...) Hoy debe pensarse hasta qué punto ese "cerco hermético", tildado de sustrato oscurantista y refugio de superstición, no forma parte de un concepto más rico y más complejo de logos, pensar-decir (1991, pp. 516-521).

Necesitamos, pues, de lo que quizás no sea erróneo llamar razón integral o razón abierta, una razón acorde con la compleción o completitud de la experiencia humana, y abierta a ella ${ }^{5}$.

¿Cómo perfilarla? Quizás sea, precisamente, esta misma experiencia humana la que, considerada en la totalidad de sus dimensiones, nos pueda servir de guía primera para la comprensión auténtica del término razón o racionalidad al que ahora nos estamos refiriendo. Como ha recordado Giussani a este respecto,

la razón es ese acontecimiento singular de la naturaleza en el cual esta se revela como exigencia operativa de explicar la realidad en todos sus factores, de manera que el hombre se vea introducido en la verdad de las cosas. Así pues, la realidad emerge en la experiencia y la racionalidad ilumina sus factores. Decir "racional" es afirmar la transparencia de la experiencia humana, su consistencia y profundidad; la racionalidad es la transparencia crítica -esto es, que se da mediante una visión totalizante- de nuestra experiencia humana $(2000$, p. 141).

\footnotetext{
5/ En algunos de sus discursos como Papa, Josef Ratzinger ha hablado en un sentido más o menos semejante de "razón ampliada". Por ejemplo: Fe, razón y universidad. Recuerdos y reflexiones. Discurso en la Universidad de Ratisbona (12/09/2006). Disponible en: https://w2.vatican.va/content/benedict-xvi/ es/speeches/2006/september/documents/hf_ben-xvi_spe_20060912_university-regensburg.html
} 
Desde esta perspectiva, toda investigación que busque alcanzar algún conocimiento de la verdad, del bien o de la belleza -por parcial y limitado que ese conocimiento sea- debería reconocer dos cosas. La primera, que el punto de partida ha de establecerse en una realidad que resulte accesible a nuestra multiforme experiencia, elevarse después al plano de la reflexión y, por fin, regresar a la realidad para contrastar sus respuestas dejándose medir por ella tanto en sus conclusiones como en las variadas repercusiones personales y sociales de aquellas. $\mathrm{Y}$, en segundo lugar, que la realidad no es monolítica y que quien conoce es la persona en su integridad (dado que hay una íntima conexión entre nuestra búsqueda de la verdad, del bien y de la belleza, nuestros dinamismos cognoscitivo, volitivo y afectivo se hallan en permanente sinergia).

En consonancia con estas dos premisas, nuestro proceder exige pues tomar siempre como base inicial un "hecho", es decir, una verdad que o bien se me impone con evidencia inmediata o bien puede ser demostrada de algún modo. Pero, siempre, se trata en última instancia de un dato que se presenta ante alguien y que, por tanto, ha de ser necesariamente discernido y juzgado. $Y$, aunque dicho discernimiento tiene lugar en el plano intelectual, en realidad se lleva a cabo a través de muy diversos canales cognoscitivos, principios y medios en relación a los cuales ese hecho se me descubre con un significado, con un valor de conocimiento y de verdad, de bien y de belleza propios: no se trata, pues, de un hecho bruto, neutro, aséptico, sino lleno de matices y aspectos que podrán ser afrontados por diversos caminos y desde distintas preconcepciones.

En este sentido, objetivamente, ni todos los hechos son similares, ni son accesibles a través de un único tipo de experiencia: así, hay hechos pertenecientes al plano de la experiencia ordinaria y del sentido común, hechos científicos, hechos matemáticos, hechos filosóficos (como el de la existencia de las cosas, la realidad del devenir, del pensamiento, del deseo, de la libertad y del amor...), hechos de naturaleza estética y/o artística, hechos morales e incluso hechos religiosos. $Y$ cada uno requiere de un proceso de verificación de sus conclusiones que sea apropiado tanto al tipo de objeto como a la forma de experiencia por la que de ellos nos hacemos cargo.

Lo que de este modo se sigue es un rechazo frontal de cualquier género de reduccionismo, ya sea ontológico o epistemológico. Lo real, por ejemplo, no podrá ser caracterizado ya solo por su capacidad de interacción con entidades cuyo existir se me impone de forma intuitiva (a través de la percepción sensible o de la autoconciencia) y es captado en un juicio existencial elaborado por mi inteligencia; también podrá ser objeto de un razonamiento analógico que se sustenta y resuelve tanto en los hechos como en los principios primeros (identidad, contradicción, causalidad) que guían el acontecer de la realidad y el proceder de esa misma inteligencia. Y para profundizar y progresar en la búsqueda de la verdad, para tratar los hechos y establecer conclusiones firmes a partir de ellos -especialmente los hechos referidos al ser humano-, nuestras intuiciones primeras deberán combinarse con el discurso, la observación (sensible o introspectiva) con el análisis, el conocimiento especulativo con el conocimiento práctico y aun con el conocimiento por connaturalidad (que poseemos por la imbricación de la inteligencia con nuestras facultades sensitivas y apetitivas, y que sirve de cauce para las experiencias moral, poético-artística y religiosa), el plano de lo inteligible con el de lo vivencial, la razón con la voluntad y el "corazón", la reflexión personal con el diálogo.

Todo eso abarca la totalidad de nuestra experiencia y hasta esos extremos alcanza el 
ensanchamiento de los horizontes propio de lo que he llamado "razón abierta", una razón que -en palabras de Benedicto XVI- tiene como rasgos propios ser amplia y confiada:

amplia porque (...) está abierta a todo el ser y, por tanto, también a las cuestiones fundamentales e irrenunciables del vivir humano; y confiada porque (...) promueve una civilización que reconoce la dignidad de la persona, la intangibilidad de sus derechos y la obligatoriedad de sus deberes (Ratzinger, 2010).

2. El otro polo de la relación que estoy intentando establecer está constituido por la fe (religiosa). También en esta podemos percibir diversas concepciones que es preciso analizar. Considerada grosso modo, distinguiré básicamente dos variantes.

a) Por un lado, estaría la fe típica de los fundamentalismos religiosos. No solo se concibe -tanto por su origen como por su alcance- como superior a la razón, sino, frecuentemente, incluso como opuesta a ella. ¿Por qué habría de llegar a ser así? Por cuanto se interpreta a la razón como una suerte de falso ídolo que osaría someter a análisis la palabra supuestamente revelada por el verdadero Dios y amenazaría con poner en cuestión la adhesión del creyente a su religión. Con estos presupuestos, además, no solo se separaría la razón de la fe sino que se la desgajaría también de la libertad y del sentimiento, convertidos entonces en los únicos medios propiamente humanos en los que el creyente podría sostener su convicción.

Resulta evidente que, con una concepción como esta, que podemos denominar fideísta y que desemboca casi de un modo inevitable en reduccionismos moralistas y puramente legalistas de lo religioso, resulta prácticamente imposible establecer todo principio de diálogo con el ateísmo de hoy, habitualmente poco receptivo cuando no manifiestamente hostil a cualquier pretendido encuentro con una realidad que se dice trascendente. Pero es que, por otro lado, parece difícil de ese modo evitar también una cierta disociación en la persona y en la vida del propio creyente. Mencionada ya la separación que así se establece en su interior entre la razón y los órdenes volitivo y afectivo, a ella habría que añadir igualmente el peligro de disociación entre su vida cotidiana y su vida de fe, entre la vida secular y la vida religiosa, entre lo temporal y lo espiritual.

Aunque pueda resultar sorprendente, cuando ateos como Richard Dawkins, Sam Harris o Christopher Hitchens, por citar solo tres ejemplos significativos, pretenden atacar la fe religiosa (en particular, los monoteísmos), en realidad lo que están haciendo es poner en cuestión esta concepción puramente voluntarista y/o emotivista que ellos conectan además con toda suerte de intolerancias y violencias, y que en su opinión tienen como apoyo último textos pretendidamente sagrados como el Antiguo Testamento o el Corán (que interpretan de modo indiscriminado y sin demasiada sutileza ni conocimientos especializados). De ese modo, esos ateos toman una parte por el todo y no distinguen entre la inmensa diversidad de culturas y religiones: desatendiendo la diversa manera

6/ Puede encontrarse un tratamiento más detenido de esta "razón ampliada", enmarcada en la concepción de lo que llamo una "antropología integral", en Autor (2013). 
en que conciben y ejercitan la razón o la conciencia moral, concluyen que todas ellas pueden ser juzgadas de forma similar.

b) Hay, de hecho, otra forma de concebir la fe bien distinta del fideísmo, que no está expuesta a estos peligros más que en la medida en que toda forma de fe (y de razón) se hallan encarnadas en nuestra débil y limitada condición, y que sí creo que puede servir de sólida base y buen punto de partida para la relación armónica y fructífera con la razón que estoy intentando construir en orden a una reflexión y un diálogo serenos sobre Dios. Me refiero a aquella concepción de la fe cristiana que mantiene la firme convicción de que «una fe sin anclaje en la inteligencia no es una [verdadera] fe cristiana» (Torralba Roselló, 2000, p. 247).

De acuerdo con esta concepción, de manera semejante a lo que sucede en su ámbito con el amor, se puede decir de la fe que es en cierto sentido "trans-racional" (que va más allá de la razón y no puede reducirse a esta) pues apunta hacia algo que la trasciende e implica a la persona en todas sus dimensiones (no solo la cognoscitiva, también la volitiva y la afectiva); pero, igualmente, se ha de afirmar que es "razonable" en la medida en que no se nos presenta como algo absurdo, es capaz de animar una vida interior y exterior sin discordancias y, además, se corresponde con las aspiraciones más profundas del ser humano ínsitas en nuestra naturaleza y accesibles a nuestra experiencia común. A este respecto, profundizando en el marco histórico de surgimiento de la idea cristiana de Dios que más arriba hemos bosquejado, Ratzinger dice:

Los Padres de la Iglesia han visto la prehistoria de la Iglesia no en las religiones sino en el movimiento de la razón comenzado con Sócrates (...) Tenemos algo que es comunicable y ante lo cual la razón, que lo estaba esperando, sale al encuentro. Es comunicable porque pertenece a nuestra naturaleza humana común. La racionalidad era, por tanto, postulado y condición del cristianismo, y permanece como una herencia europea para confrontarnos, de modo pacífico y positivo (Ratzinger y Della Logia, 2004).

No se trata pues de suprimir o eximir al creyente, con la respuesta de la fe, del ejercicio de la racionalidad. Lo que al menos en ciernes podemos descubrir aquí es la reivindicación de una razón humana capaz de ensanchar sus horizontes de modo que haga justicia a la totalidad de nuestra experiencia y de lo real, tal y como más arriba expuse. Para ello, conviene que la teoría científica delimite bien sus métodos propios y sus relaciones con los demás saberes. Pero en orden a que esa reivindicación pueda ser creíble y aun legítima, la fe -como vemos- tiene también mucho trabajo que hacer respecto de sí misma, un trabajo de clarificación y de purificación, de ponderación de la información que nos proporciona la ciencia y de profundización en su inexcusable relación con la razón, para estar a la altura de la dignidad humana. Creo que solo así será posible restablecer el encuentro entra razón y fe, ahora de un modo nuevo y más sólido.

El prolongado y famoso diálogo entre Habermas y Ratzinger me parece que es una buena muestra de esta nueva relación que aquí persigo cimentar. Y sus conclusiones me parecen justas y ecuánimes: 


\begin{abstract}
Hemos visto -dice concretamente Ratzinger- que en la religión existen patologías sumamente peligrosas, que hacen necesario contar con la luz divina de la razón como una especie de órgano de control encargado de depurar y ordenar una y otra vez la religión, algo que, por cierto, ya preveían los Padres de la Iglesia. Pero, a lo largo de nuestras reflexiones, hemos visto igualmente que también existen patologías de la razón de las que la humanidad, por lo general, hoy no es consciente. Existe una desmesurada arrogancia de la razón que resulta incluso más peligrosa debido a su potencial eficiencia (...) Por eso, también la razón debe, inversamente, ser consciente de sus límites y aprender a prestar oído a las grandes tradiciones religiosas de la humanidad. Cuando se emancipa por completo y pierde esa disposición al aprendizaje y esa relación correlativa, se vuelve destructiva (2006, pp. 66-67).
\end{abstract}

\title{
3.2.2. El diálogo y sus condiciones de posibilidad
}

Otro ejemplo que está demostrando ser fructífero comenzó a ponerse en práctica en diciembre de 2009, cuando el Papa Benedicto XVI promovió la creación de lo que se dio en llamar el "Atrio de los Gentiles". Su dirección, realización y desarrollo le fue encargada al Pontificio Consejo para la Cultura dirigido entonces por el Cardenal Gianfranco Ravasi. ¿Cuál era la intención del Papa y por qué le dio ese nombre? A imagen y semejanza del "atrio de los gentiles" del antiguo Templo de Jerusalén, un lugar dentro del templo pero fuera del espacio propiamente sagrado en el que los no creyentes en la fe de Israel podían encontrarse con los escribas, dialogar sobre la fe e incluso orar al Dios desconocido, se trataba de una iniciativa que buscaba tender puentes de diálogo entre personas de distintas convicciones, particularmente entre creyentes y no creyentes, acerca de los grandes interrogantes de la existencia humana.

El primer encuentro, celebrado en París durante los días 24 y 25 de marzo de 2011, reunió a intelectuales y jóvenes representativos de los diferentes horizontes científicos y culturales, y estaba orientado principal -aunque no exclusivamente- al encuentro de los creyentes con los "ateos convencidos", aquellos en los que a menudo sobrevive una auténtica pasión por lo divino. Preocupados por la situación actual del hombre y deseosos todos de «un mundo nuevo y más libre, más justo y más solidario, más pacífico y más feliz», compartieron sus inquietudes y sus reflexiones, sus propuestas y sus vivencias. Después de París, estaba previsto que tuvieran lugar otras etapas del diálogo entre creyentes y personas indiferentes, aquellos que mantienen una relación provocadora con la religión etc., en ciudades diversas a lo largo y ancho del mundo. Y así ha sucedido, en efecto: Florencia, Bolonia, Palermo, Estocolmo, Bucarest, Tirana, Barcelona, México, Washington, Buenos Aires, Curitiba, Río de Janeiro o la propia Ciudad del Vaticano han visto sucederse los encuentros y las diversas etapas de este diálogo prometedor y, en algunos aspectos, ya ciertamente fecundo.

Pero más allá de los hechos, de las expectativas creadas por esta iniciativa y de sus logros hasta el día de hoy, lo que me importa ahora es intentar fijar las condiciones para que, en general, cualquier diálogo de esta naturaleza pueda llevarse a cabo con esperanzas de éxito. En el mundo intelectual, político y religioso hoy se habla mucho de diálogo y, no pocas veces, ese término acaba lastrado por una gran ambigüedad. Importa, pues, ya en principio, delimitar lo mejor posible lo que por él se entiende. Para ello, propongo la siguiente definición, tomada de Luigi Giussani: 
Diálogo es una propuesta al otro de lo que yo veo y una atención a lo que el otro vive, porque estimo su humanidad y porque le amo. Lo que de ningún modo implica este diálogo es una duda sobre mí, ni tampoco negociar lo que yo soy (2005, p. 124).

Aplicada a nuestra circunstancia, podríamos entresacar de esta noción las siguientes notas, que caracterizo brevemente:

a) En primer lugar, un diálogo entre creyentes y no creyentes no puede ser simplemente una parte o aspecto de lo que podríamos llamar la conversación general de la humanidad. Se trata de hablar nada menos que sobre Dios, un tema que, independientemente de que tenga o no un referente real, no puede ser banalizado ni trivializado, y cuya presencia/ausencia ha tenido y sigue teniendo una enorme importancia para muchos seres humanos y para la historia de la humanidad en su conjunto.

b) Además, la finalidad de este diálogo -como sucede en todo auténtico diálogo- es buscar la verdad. El diálogo acerca de Dios se debe desarrollar, por lo tanto, en el horizonte de aquella y requiere en todos los participantes de una apertura al menos implícita a la dinámica de lo veritativo, y de una cierta confianza en la razón humana a la hora de encarar con honestidad y decisión las cuestiones fundamentales de la existencia que a todos nos inquietan y atañen, a partir de las propuestas de cada uno y de una respetuosa atención a las de los demás.

El diálogo no consiste, pues, en la adopción de posturas de compromiso, ni en buscar una "verdad" que sea resultado, sin más, de una especie de consenso. Como precisó Habermas desde posiciones ajenas a toda fe religiosa, pero también conscientes de las propias limitaciones y, por ende, abiertas a la interlocución:

No debemos eludir la alternativa entre una mirada antropocéntrica y la mirada desde la lejanía del pensamiento teocéntrico y cosmocéntrico. Pero no es lo mismo hablar los unos con los otros que los unos sobre los otros. Para ello deben darse dos condiciones: el lado religioso debe reconocer la autoridad de la razón "natural" $y$, por tanto, los resultados falibles de las ciencias institucionalizadas, así como los fundamentos de un igualitarismo universalista en el ámbito del derecho y la moral. $\mathrm{Y}$, viceversa, la razón secular no debe erigirse en juez de las verdades de fe, aun cuando del resultado solo acepte como razonable lo que pueda traducir a sus propios discursos, accesibles en principio de manera universal (Habermas, 2009, pp. 56-57) ${ }^{7}$.

Frente a lo que muchas veces se dice, tampoco la duda puede servir, en ningún caso, de método o de punto de partida. No hace falta poner entre paréntesis lo que uno cree para que el diálogo pueda desarrollarse. Dudar será algo que pueda venir después, como estímulo que procede de mi interlocutor y de mi propia reflexión a partir de lo que él dice, y que resulta

7/ Esta obra incluye los debates que Habermas tuvo en Munich con algunos miembros de la Escuela Superior de Filosofía de los Jesuitas, en octubre de 2007. Dio a su intervención el sugerente título de "Una conciencia de lo que falta". 
factible por el hecho de que, al tratar de Dios, tanto el creyente como el ateo se sitúan en la frontera de sus respectivas certezas. Esta dubitabilidad segunda, por otra parte, podrá facilitar la consolidación de la comunicación entre los interlocutores.

c) En relación con quienes conversan, ese diálogo necesita igualmente de la apertura apasionada, sincera y comprometida al misterio del hombre que somos y de la realidad en la que vivimos. Dicha apertura, movida en última instancia por el interés por todo lo humano, debería no solo ser capaz de despejar prejuicios sino de permitir incluso la aceptación o el rechazo de cualquier conclusión si la reflexión llevada a cabo "con toda el alma" así lo exigiera.

d) Para ello, es obvio que el diálogo no debe centrarse solo en los aspectos comunes, lo cual llevaría al estancamiento, ni mucho menos consistir en meros encuentros dialécticos sin que los participantes defiendan afirmaciones y actitudes sustantivas e incluso atrevidas desde sus diversos puntos de vista. Pero tampoco puede limitarse a un mero confrontar de opiniones orientado a intentar demostrar las falacias en los argumentos del otro, ni buscar la polémica por la polémica. Dicho de otro modo, ni los creyentes pueden encararlo desde una actitud de apologética feroz ni los no creyentes desde posiciones irreverentes o irrespetuosas. Hablar de Dios no consiste únicamente en un intercambio de palabras; implica también una conversación del corazón y de la mirada que busca la verdad. Se trata de dialogar para aprender, más que para rebatir o para simplemente divagar.

e) Por último, el diálogo debe partir de la certeza acerca del valor y de la dignidad humana, y por tanto, del afecto y la consideración por todo hombre como "alter ego" (el otro, que es a la vez mi "distinto" y mi semejante). También él es partícipe de deseos, de dudas, de alegrías y sufrimientos, amén de depositario de convicciones y experiencias capaces de enriquecerme. Y con él, se trata de buscar como principal objetivo la promoción de esa misma dignidad en todas sus dimensiones.

En definitiva, creo que solo desde estas posiciones, convicciones previas y actitudes, propias de sinceros y honestos buscadores, podemos esperar que, en medio de grandes dificultades que habrá que ir superando con el impulso de nuestro común amor a la verdad, nuestra pasión por la realidad e inmensas dosis de buena fe, avancemos en nuestro encuentro o, cuanto menos, nos respetemos unos a otros de forma algo más positiva que el respeto vacío propio de la indiferencia. En última instancia, como Unamuno, también yo

abrigo la profunda creencia de que, si todos dijésemos siempre y en cada caso la verdad, la desnuda verdad, al principio amenazaría hacerse inhabitable la tierra, pero acabaríamos pronto por entendernos como hoy no nos entendemos. Si todos nos viéramos desnudas las almas, nuestras rencillas se fundirían en una inmensa piedad mutua (1978, p. 22). 


\section{Bibliografía}

ÁLVAREZ ÁLVAREZ, Juan Jesús (2013). Aproximación crítica a la Inteligencia Artificial. Claves filosóficas y prospectivas de futuro. Pozuelo de Alarcón (Madrid): Universidad Francisco de Vitoria. Colección Diálogos.

DAWKINS, Richard (2010). El espejismo de Dios. Madrid: Espasa Hoy.

FERNÁNDEZ RECUERO, Ángel L. (2016). Tender puentes: una conversación con Javier María Prades y Juan José Gómez Cadenas. Jot Down, . Recuperado de: http://www.jotdown.es/2016/05/tenderpuentes-una-conversacion-con-javier-maria-prades-y-juan-jose-gomez-cadenas

GIUSSANI, Luigi (2000). El sentido religioso. Curso básico de cristianismo. Volumen I. Madrid: Encuentro.

GIUSSANI, Luigi (2005). II Rischio educativo. Milano: Rizzoli.

HABERMAS, Jürgen (2009). Carta al Papa. Consideraciones sobre la fe. Barcelona: Paidós.

HADJADJ, Fabrice (2013). ¿Cómo hablar de Dios hoy? Manual de anti-evangelización. Granada: Nuevo Inicio.

ISRAEL, G. (2008, 16/01). Quando Ratzinger difese Galileo alla Sapienza. Osservatore Romano, 16 enero. Recuperado de: http://www.gliscritti.it/approf/2008/papers/israel160208.htm

MÜLLER, Gerhard (2016). Informe sobre la esperanza. Madrid: BAC.

PASTORINO, Miguel (2016). ¿En qué Dios creemos? ¿Contra qué Dios arremeten los ateos actuales? ¿De quién hablan los que creen y los que no creen cuando usan su nombre? ¿Hablamos todos de lo mismo cuando decimos "Dios? Aleteia. Espiritualidad, 18 enero. Recuperado de: http:/l es.aleteia.org/2016/01/18/en-que-dios-creemos/

RATZINGER, Joseph (2005). Introducción al cristianismo. Salamanca: Sígueme.

RATZINGER, Joseph (Benedicto XVI). (2010). Audiencia General de 16 de junio dedicada a Santo Tomás de Aquino (2). Recuperado de: http://w2.vatican.va/content/benedict-xvi/es/audiences/2010/ documents/hf_ben-xvi_aud_20100616.html

RATZINGER, Joseph y DELLA LOGIA, Galli (2004). La fuerza de la razón contra el relativismo. Diálogo entre el cardenal Ratzinger y el historiador Galli della Loggia. I/ Foglio, 27-28 de octubre.. Recuperado de: https://www.aceprensa.com/articles/la-fuerza-de-la-raz-n-contra-el-relativismo

RATZINGER, Joseph y HABERMAS, Jürgen (2006). Dialéctica de la secularización: sobre la razón y la religión. Madrid: Encuentro.

RODRÍGUEZ DUPLÁ, Leonardo (2006). Dialéctica de la secularización: sobre la razón y la religión. Madrid: Encuentro. 
RUSSELL, Bertrand y COPLESTON, Frederick (1978). Debate sobre la existencia de Dios. Valencia: Revista Teorema.

TORRALBA ROSELLÓ, Francesc (2000). ¿Por qué creer? La razonabilidad de la fe. Barcelona: Edebé, TRESMONTANT, Claude (1969). Cómo se plantea hoy el problema de la existencia de Dios. Barcelona: Península.

TRÍAS, Eugenio (1991). Lógica del límite. Barcelona: Destino.

UNAMUNO, Miguel de (1978). Mi religión y otros ensayos breves. Madrid: Espasa-Calpe. 